\title{
Lecturer Supervisors' Perspectives on Challenges in Online Thesis Supervision
}

\author{
Djatmika Djatmika ${ }^{1}$, Lastika Ary Prihandoko $^{2 *}$, and Joko Nurkamto ${ }^{3}$ \\ ${ }^{1,3}$ Universitas Sebelas Maret \\ ${ }^{2}$ Universitas Musamus Merauke \\ *Corresponding author. Email: prihandoko@unmus.ac.id
}

\begin{abstract}
The Covid-19 epidemic has resulted in an offline-to-online shift in EFL undergraduate thesis supervision, with all of its associated difficulties. As a result, this qualitative study used a constructivist epistemology to look at the challenges of online EFL thesis supervision from the perspective of the lecturer supervisors. 23 lecturer supervisors from higher educational institutions in Central Java and Papua were engaged as the participants. The data were gathered using In-depth interviews. The data were further analyzed according to the interactive model of analysis. The findings revealed a number of challenges in online thesis supervision, including being in the processes of adjusting to the shift from offline to online thesis supervision, ineffective communication between supervisors and students, a lack of time to always access online media, difficulties faced by students in collecting field data, and a decrease in students' active participation in online thesis supervision. More research is expected to be done on the same topic as this study's, but with more participants from other Indonesian regions. Such research might help confirm our present results and might add to the body of knowledge about online thesis supervision in Indonesia.
\end{abstract}

Keywords: EFL undergraduate thesis, online thesis supervision, challenges in online thesis supervision

\section{INTRODUCTION}

The global epidemic of Covid-19 has posed challenges for both lecturer supervisors and students in terms of all academic activities at universities, where academic activities must now be conducted online [1]. Many countries, including Indonesia, suffer from the aforementioned. Such an offline-to-online transformation is challenging because two factors, technological competence and facilities, can become potential problems that stymie the successful continuation of online educational activities, such as curricular administration, learning, and thesis supervision, at any time. Pramana et al., for example, found that the most popular platform for online learning implementation in Indonesian institutions is the Whatsapp application, which is the most basic social media application, and that poor internet signals are the most common source of learning inefficiency [2]. Their research revealed that technology skills and resources are at the heart of online learning issues. Efriana's and Yudiawan's investigations have both corroborated these issues [3] [4].

Regardless of the covid-19 issue, many studies have been conducted over the last five years at various levels of educational institutions in various countries to address the issues of online learning, e-learning, distant learning, and the like, but only a few have focused on online thesis supervision. For example, Huang's research showed online learning issues in terms of teacher roles, finding that students do not view instructors' cognitive, emotional, or management responsibilities as predicted [5]. Gómez-Rey et al. described online learning issues as clashing expectations between teachers and students [6]. Martin et al. conducted a research that underlined the significance of lecturer supervisors' active reactions in helping students address issues with online learning [7]. Furthermore, research conducted by Barclay et al. and Thongsri et al. underlined the relevance of technical facilities and technological skill as factors for dealing with online learning issues [8] [9]. Prior research on the issues or limitations of online thesis supervision is, however, rare in the university context. Until now, the majority of studies on thesis supervision issues have been conducted in the offline manner. For example, OrtizCatalan et al. found that thesis supervision is challenged by a lack of available supervision time and a lack of structural efficiency in supervision [10]. Students' unfavorable impressions of thesis supervision are exacerbated by ambiguous interventions and full control of thesis supervisors [11]. Following this, Almeatani et al. found that the distance between thesis supervisors 
and students had an impact on the efficacy of interactions during thesis supervision [12].

To our knowledge, very few or no earlier research have addressed the issues or concerns in the context of online thesis supervision, as stated above. This gap in the literature is addressed in our research. Because the global and national phenomenon of the covid-19 has an impact on the offline-to-online transformation of any academic activities at universities, and because there are few previous studies on thesis supervision done in the context of online thesis supervision, the current study aims to address the challenges of online EFL undergraduate thesis supervision.

\section{LITERATURE REVIEW}

\subsection{EFL Undergraduate Thesis}

The EFL undergraduate thesis is a type of academic writing that tackles themes or variables in the discourses of EFL education and linguistics. It should be researchbased. Undergraduate thesis is the final step in the process of earning a bachelor's degree for undergraduate students [13]. A thesis, as part of the academic writing genre, is a sort of interactive communication between the writer and the reader in which the writer analyzes an issue in detail based on data with the objective of giving the readers with accurate information. As previously said, academic writing is challenging to master since the phases include intellectual tasks such as brainstorming ideas, planning, sketching a conceptual framework of what to write, writing drafts, correcting, and editing [14]. An academic writer must not only be accurate and fluent in the use of academic words, collocations, phrases, and grammar [15], [16], but he must also be capable of mapping references related to the discourse under consideration [17] and constructing arguments with clear and understandable idea organization [18]. According to $\mathrm{Wu}$ et al, undergraduate students go through six phases while writing a thesis: determining the research topic, reviewing relevant literature, and conducting the research project, writing the first draft of the thesis, revising and finalizing the thesis [19]. Introduction, literature review, research methods, results or findings and discussions, conclusions and recommendations, and references are the six general parts of a thesis. Each of these components has an own set of movements [20]. Each stage and part of thesis writing has a different amount of effort and complexity [21]. As a result, students require supervision from experienced supervisors who are proficient in a variety of supervisory styles and methods. The quality of a student's work is determined by the supervisor's supervision style, or how he or she interacts with and responds to students during thesis supervision [22].

\subsection{Thesis Supervision}

In order to complete their theses as quickly as possible, undergraduate students must be devoted and enthusiastic about their subjects of study [23]. Thesis supervision is characterized as a collaborative, dynamic, and multifaceted interaction between supervisors and students that includes emotional and cognitive aspects in order to assist students in finishing their theses [24], [25]. Good communication procedures and supervision patterns that adapt to students' requirements, according to Filippou et al., characterize effective thesis supervision [24]. Students and supervisors have two aspects [26]. The first dimension is about giving instructions and writing guidelines. The topic of research is the emphasis of the second dimension. According to Agricola et al., supervisors should be able to make decisions that are centered on the students' affective dimensions, such as empowering students to build arguments and paying attention to their social needs; decisions that are centered on the supervisors' cognitive dimensions, such as checking and improving students' understanding; and decisions that are centered on the supervisors' cognitive aspect [11].

The supervisors' patterns of interactions and methods in reacting to students' thesis writing become significant features to include in thesis supervision, and these characteristics affect the quality of students' theses, especially given the protracted period of thesis writing [22]. From the moment they choose appropriate research subjects through the time they submit reports on the findings of their research projects, students require competent supervision from their supervisors. As a result, thesis supervision necessitates the supervisors' ability to create good, personal, and professional connections with students, as well as a mix of academic knowledge and skillful management [23]. Supervisors are in responsible of controlling the frequency of interactions with students, taking into consideration their schedules, providing advise, and delivering useful feedback. Supervisors are required to be able to play a variety of roles throughout supervision procedures, including being challengers to stimulate students' cognitive growth, providing emotional support, and mentoring students' ability to write theses effectively [24].

The global Covid-19 epidemic, which has an influence on learning shifts from offline to online modalities, has a comparable impact on thesis supervision shifts. This has, of course, posed difficulties for supervisors and students, on top of the already complicated thesis supervision processes. Online supervision is conceivable, and it is at some point viewed as an effective solution, where interactions between supervisors and students are mediated by technological devices such as computers, email, and various social media applications, due to the flexibility provided by technological advancements [27]. If wellorganized, online thesis supervision can save time [28]. Almeatani et al., for example, conducted previous studies that reflected the shift to online thesis supervision. They sought to build a regulated platform to enable thesis supervision procedures that did not need supervisors and students to meet face-to-face, based on the issue of ineffective interactions between supervisors and students. The thesis supervision mobile system was the platform's name. Students were able to finish their 
thesis on time because of this platform. Each element of supervision was successfully managed by both students and supervisors. The site also made it easier to keep track of the development of the thesis electronically. Management, supervisors, and students could all look over the platform and keep an eye on it. This portal may also be accessed by students and supervisors via their mobile phones. Students may keep track of any thoughts on thesis supervision that came to mind at any time and in any location. Supervisors were also aided in providing appropriate comments on students' theses [12]. Nasution et al. have undertaken a similar attempt to build a platform for thesis supervision [29]. Apart from the efficiency of online thesis supervision, CasadoLumbreras and Colomo-Palacios pointed out that the procedure of online thesis supervision does not always go well, which might contribute to negative impressions among students. Students, for example, may be perplexed by the supervision process, have trouble comprehending their online research projects, be unsure of supervisors' duties, and have difficulty working on their research projects [30].

\subsection{Challenges in Thesis Supervision}

If thesis supervision does not function well, factors such as supervision methods, instructors, and students all contribute to obstacles and issues. When it comes to thesis supervision, the most common issues include a lack of supervision time, a poorly managed supervision system, supervision procedures that do not meet students' expectations, and insufficient facilities for supervisor-student interactions. One of the causes for the low quality of student theses is because supervisors are too busy to supervise them. Another factor is the lack of effective patterns that underpin thesis supervision [10]. According to Agricola et al., students anticipated their supervisors to provide well-organized supervision procedures, and they were likely to have unfavorable impressions if such processes were not developed [11]. It is clear that Agricola et al. stressed the significance of satisfying students' expectations when supervising theses [11]. Furthermore, Almeatani et al. found that insufficient interaction facilities are a key hindrance to the efficacy of thesis supervision, therefore their study aimed to create a mobile thesis supervision system that students may access via their mobile phones. The thesis supervision mobile system supports students in finishing their theses on time by facilitating effective and efficient communication between supervisors and students [12].

Supervisory obstacles and issues are frequently linked to supervisory responsibilities and supervising techniques that are unsuitable. Students are more likely to feel disappointed when their supervisors try to give them total authority all of the time. Students are not given the chance to make arguments, develop ideas, or be creative in the construction of information relevant to the research focus they are working on in this situation [11]. The acceptance of supervising styles, according to Casado-Lumbreras and Colomo-Palacios, will have a big impact on the efficacy and smoothness of supervisory procedures. Students who are unfamiliar with their supervisors' methods (for example, supervisors who blend the styles of a mentor and a supervisor) are sometimes perplexed and find it difficult to complete their theses as quickly as they would expect [30].

The low level of students' foreign language abilities as a tool to access international sources, inadequate academic writing knowledge and skills, and low selfefficacy in academic writing skills are all common obstacles in thesis supervision procedures. MalagaToboa et al. looked at students' electronic reading sources while they were working on their theses. The majority of their participants, according to their research, prefer to use Polish-language publisher websites. This is due to the students' limited English abilities, which prevent them from absorbing information from scientific publications published in international journals, which are predominantly written in English. They found that having limited reading resources had a negative influence on the quality of students' theses [31]. Following that, Casado-Lumbreras and Colomo-Palacios published a research that detailed some of the issues that their student participants had. Many of the people who took part in the study stated that they lacked the necessary knowledge and abilities to write academic papers. Some participants expressed doubts about their ability to finish their theses [30].

\section{METHOD}

The current study used the constructivist paradigm [32] to undertake a qualitative inquiry into the problems of online thesis supervision from the perspective of the lecturers. Instead of seeking quantitative data on this topic, we reasoned that obtaining qualitative data would be more useful and relevant to readers and other academics working on a similar topic.

\subsection{Participants}

We recruited lecturer supervisors from Java and Papua to participate in the qualitative inquiry since we, the authors of this article, have worked as active instructors at universities in both Java and Papua over the course of our research. For the purpose of selecting the participants, we used a technique known as purposive sampling. In order to accomplish this, we established certain criteria for purposive sampling. First and foremost, the participants were instructors with sufficient expertise in thesis supervision for undergraduate students studying English as a foreign language. Second, communication with the participants was made simple through the use of the internet. Third, all of the participants agreed to participate in this study on their own initiative. There were a total of $464 \mathrm{EFL}$ lecturers in the study, and there were 23 lecturer supervisors who matched the requirements for the purposing sampling described above. As a result, 23 lecturer supervisors were recruited to participate in the qualitative research. 


\subsection{Data Collection and Analysis}

In-depth interviews were used in the qualitative research to gather detailed and contextual information about the perspectives of lecturer supervisors on the challenges of online thesis supervision. Miles et al. recommended that the qualitative data be analyzed using an interactive model [33]. We performed four elements of analysis based on this model: data collection, data condensation, data display, and conclusion. Data was gathered through in-depth interviews, as previously stated. To make it easier to present the data, the information gathered from interviews was grouped based on emerging representative themes. The data were presented in a logical order based on their themes when it came to data presentation. The data presentation was followed by a discussion of the data as well as our scientific interpretations. In order to arrive at a representative conclusion, the data findings, discussions, and interpretations were thoroughly reviewed.

\section{FINDINGS}

The information gathered from interviews about the challenges of online EFL thesis supervision could be divided into some categories. Figure 1 shows the coded categories.

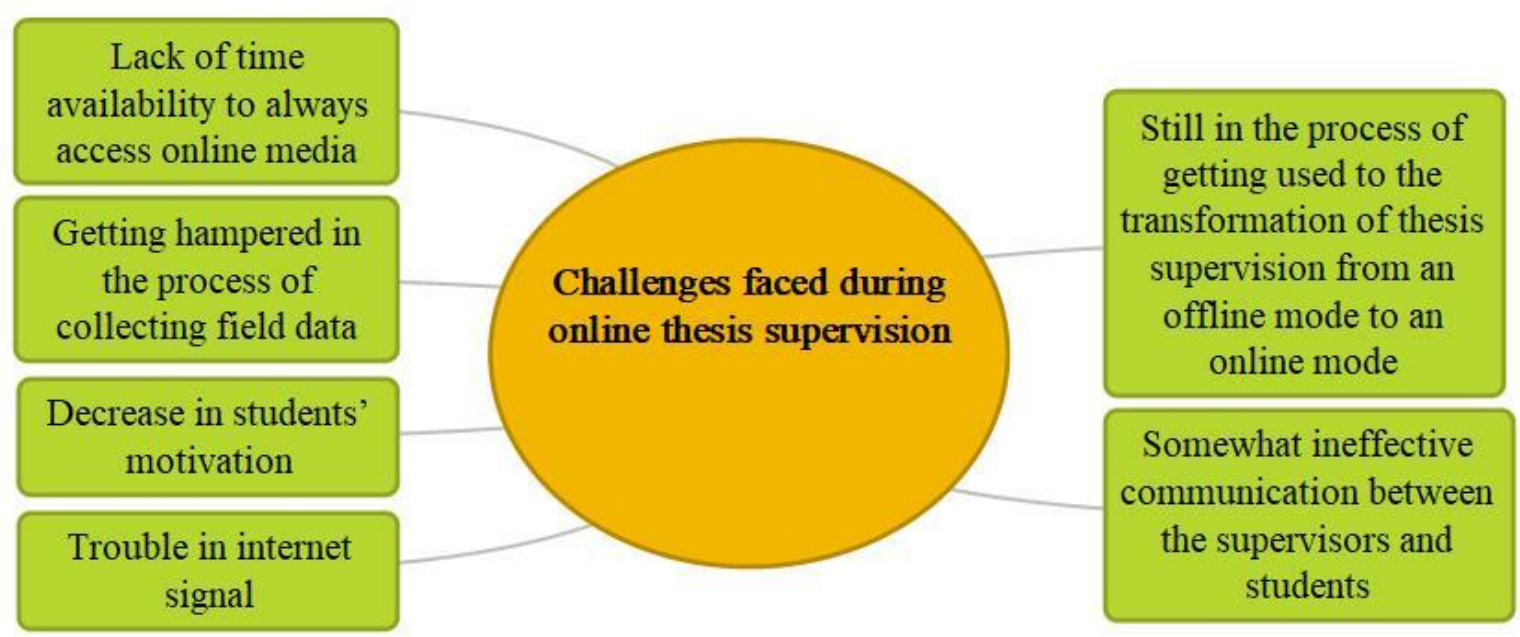

Figure 1. Challenges in Online Thesis Supervision

EFL lecturer supervisors faced six challenges during online thesis supervision, as shown in Figure 1. The first issue was that some of the thesis supervisors were still adjusting to the shift from offline to online supervision. Supervisor 14 stated the following in response to this situation, in line with what others have said.

I have a habit of forgetting to open emails from students who are working on their theses under my supervision (supervisor 14).

The second issue was that during online thesis supervision, communication between supervisors and students was ineffective. Supervisor 17 stated the following, in agreement with others who shared similar viewpoints:

My students and I have a lot of disagreements about how we should communicate. My students did not immediately contact me to talk about their problems. There could be two reasons for this. This could be due to a lack of enthusiasm and seriousness on the part of the students. Second, this could be because of the limitations of online communication systems (supervisor 17).

The supervisors' third challenge was that they did not always have time available to conduct online thesis supervision. Supervisor 2 stated the following in order to depict this condition alongside others that contain similar information.

I don't always have time to be active in front of my laptop to guide or correct my students' online theses, especially outside of campus activities, which are, of course, jam-packed with other commitments (supervisor 2).

Supervisors identified the fourth challenge as the fact that some of their students were hampered in the field while collecting data. Supervisor 5 informed the following, for example, to represent others who had similar information.

According to my observations, the problem among my students is that they have already begun conducting field studies, particularly at schools, prior to the COVID-19 attack. After Indonesia was hit by the COVID-19 outbreak, data collection was further hampered because access to schools was severely limited, and school learning was also transformed to an online mode (supervisor 5).

The supervisors noticed a drop in motivation among their students for the fifth challenge. Supervisor 23 said the following, for example, to represent others.

The main issue is that since the thesis supervision mode was changed to online, my students' 
motivation and persistence in finishing their thesis appear to have decreased (supervisor 23).

In regards to the sixth challenge, the supervisors believed that the disruption in internet signals made it difficult to maintain the expected level of online thesis supervision. Supervisor 15 made the following statement to represent others.

The internet network can sometimes cause problems for students, making online thesis supervision difficult (supervisor 15).

The supervisors' perspectives are represented in the six challenges of online thesis supervision listed above. According to the supervisors' perspectives, these challenges highlighted the difficulties faced by both supervisors and students when it came to online thesis supervision.

\section{DISCUSSION}

The goal of this study was to uncover the difficulties of online EFL undergraduate thesis supervision. It should be noted that this research took place during the covid-19 pandemic. First, this study revealed that some supervisors were still getting used to the offline-toonline transformation of thesis supervision in this discourse. Second, during online thesis supervision, communication between supervisors and students was ineffective. When compared to the face-to-face mode of supervision that the supervisors were used to, online thesis supervision had its own set of complexities. If technological competencies and facilities are not met, the offline-to-online transformation of thesis supervision could result in ineffective interactions, similar to online learning [34], [35]. As a result, ineffective interactions may result in a failure to meet students' expectations and a negative perception of supervisors among students [11]. Third, supervisors did not always have time to conduct online thesis supervision due to a lack of time availability. The foregoing was similar to Ortiz-et Catalan's al. study, which found that insufficient time for supervision is one of the reasons why students' theses are of poor quality [10]. Another reason is that the thesis supervision processes lack efficient patterns [10]. Fourth, some of their students were hampered while collecting data in the field, according to the supervisors. Because some of their students had already planned to conduct field research before the covid-19 pandemic hit Indonesia, the aforementioned challenge arose. This pandemic struck in the midst of data collection preparations. The students were then confronted with this challenge. Fifth, the supervisors believed that some of their students' motivation had dwindled. This could be due to the ineffective establishment of interactions as a result of the thesis supervision mode's transformation from offline to online. In Almeatani's et al. study, a similar situation occurred [12]. Their research also suggested developing a portable mobile application to aid in effective supervising interactions. Sixth, internet signal problems hampered the expected continuity of online thesis supervision. This is echoed in Pramana's et al. study on online learning in the Indonesian context, where the inconstancy of internet signals frequently prevents learning continuity as expected [2]. We could come up with a temporary interpretation based on the literature that internet signals appear to be part of the core problems of online learning and thesis supervision in Indonesian educational institutions.

The difficulties in online thesis supervision have been effectively depicted in this study. As a result, information about such challenges could be used as vicarious experiences [36] by other academics, educators, and thesis supervisors in order to reflect on, anticipate, and solve similar problems or challenges in thesis supervision.

\section{CONCLUSION}

Based on the perspectives of lecturer supervisors in Central Java and Papua, this study revealed a number of challenges in online EFL thesis supervision. The challenges include being in the process of adapting to the transformation of thesis supervision from an offline to an online mode, somewhat ineffective communication between supervisors and students, a lack of time available to always access online media, being hampered in the process of collecting field data, a decrease in students' motivation, and difficulties due to problems of internet signals.

More research should be done to address a similar issue as this one, but with more participants from different Indonesian provinces. Such research could help confirm on our current findings and add to the body of knowledge about online thesis supervision in Indonesia. In the Indonesian context, such literature is still scarce, and this void provides an opportunity for indepth scientific investigations.

\section{AUTHORS' CONTRIBUTIONS}

All authors have contributed to this study in a balanced manner.

\section{ACKNOWLEDGMENTS}

We would like to express our gratitude to all lecturer participants who have contributed to provide detailed data as desirable. We also thank Kementerian Pendidikan, Kebudayaan, Riset, dan Teknologi as the sponsor that has funded the completion of this study.

\section{REFERENCES}

[1] M. E. Osman, "Global impact of COVID-19 on education systems : the emergency remote teaching at Sultan Qaboos," J. Educ. Teach., pp. 1-9, 2020, doi: 10.1080/02607476.2020.1802583.

[2] C. Pramana et al., "Virtual learning during the covid-19 pandemic, a disruptive technology in higher education in indonesia," Int. J. Pharm. Res., vol. 12, no. 2, pp. 3209-3216, 2020, doi: 10.31838/IJPR/2020.12.02.430.

[3] L. Efriana, "Problems of online learning during covid-19 pandemic in EFL classroom and the solution," J. English Lang. Teach. Lit., vol. 2, no. 
1, pp. 38-47, 2021

[4] A. Yudiawan, B. Sunarso, Suharmoko, F. Sari, and Ahmadi, "Successful online learning factors in covid-19 era: Study of islamic higher education in west papua, indonesia," Int. J. Eval. Res. Educ., vol. 10, no. 1, pp. 193-201, 2021, doi: 10.11591/ijere.v10i1.21036.

[5] Q. Huang, "Comparing teacher's roles of F2f learning and online learning in a blended English course," Comput. Assist. Lang. Learn., vol. 32, no. 3, pp. 190-209, 2019, doi: 10.1080/09588221.2018.1540434.

[6] P. Gómez-Rey, E. Barbera, and F. FernándezNavarro, "Measuring teachers and learners' perceptions of the quality of their online learning experience," Distance Educ., vol. 37, no. 2, pp. 146-163, 2016, doi: 10.1080/01587919.2016.1184396.

[7] F. Martin, C. Wang, and A. Sadaf, "Student perception of helpfulness of facilitation strategies that enhance instructor presence, connectedness, engagement and learning in online courses," Internet High. Educ., vol. 37, no. March 2017, pp. 52-65, 2018, doi: 10.1016/j.iheduc.2018.01.003.

[8] C. Barclay, C. Donalds, and K. M. Osei-Bryson, "Investigating critical success factors in online learning environments in higher education systems in the Caribbean*," Inf. Technol. Dev., vol. 24, no. 3, pp. 582-611, 2018, doi: 10.1080/02681102.2018.1476831.

[9] N. Thongsri, L. Shen, and Y. Bao, "Investigating factors affecting learner's perception toward online learning: evidence from ClassStart application in Thailand," Behav. Inf. Technol., vol. 38, no. 12, pp. 1243-1258, 2019, doi: 10.1080/0144929X.2019.1581259.

[10] M. Ortiz-Catalan, A. Middleton, and M. Gustafsson, "Supervision of M.Sc. theses using the writing of a scientific article as a framework to increase efficiency and quality of research outcomes," Proc. Annu. Int. Conf. IEEE Eng. Med. Biol. Soc. EMBS, pp. 1436-1439, 2019, doi: 10.1109/EMBC.2019.8856364.

[11] B. T. Agricola, F. J. Prins, M. F. van der Schaaf, and J. van Tartwijk, "Supervisor and student perspectives on undergraduate thesis supervision in higher education," Scand. J. Educ. Res., pp. 121, 2020, doi: 10.1080/00313831.2020.1775115.

[12] M. Almeatani, H. Alotaibi, E. Alasmari, M. Meccawy, and B. Alghamdi, "Thesis supervision mobile system for enhancing student-supervisor communication," Int. J. Interact. Mob. Technol., vol. 13, no. 6, pp. 4-14, 2019, doi: 10.3991/ijim.v13i06.9533.

[13] K. F. Weaver, V. Morales, M. Nelson, P. F. Weaver, A. Toledo, and K. Godde, "The benefits of peer review and a multisemester capstone writing series on inquiry and analysis skills in an undergraduate thesis," CBE Life Sci. Educ., vol.

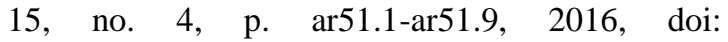

10.1187/cbe.16-01-0072.

[14] C. M. Kiriakos and J. Tienari, "Academic writing as love," Manag. Learn., vol. 49, no. 3, pp. 263 277, 2018, doi: 10.1177/1350507617753560.

[15] L. Alhassan and D. Wood, "The effectiveness of focused instruction of formulaic sequences in augmenting L2 learners' academic writing skills: A quantitative research study," J. English Acad. Purp., vol. 17, pp. 51-62, 2015, doi: 10.1016/j.jeap.2015.02.001.

[16] A. Ansarifar, H. Shahriari, and R. Pishghadam, "Phrasal complexity in academic writing: A comparison of abstracts written by graduate students and expert writers in applied linguistics," J. English Acad. Purp., vol. 31, pp. 58-71, 2018, doi: 10.1016/j.jeap.2017.12.008.

[17] A. Cumming, C. Lai, and H. Cho, "Students' writing from sources for academic purposes: A synthesis of recent research," J. English Acad. Purp., vol. 23, pp. 47-58, 2016, doi: 10.1016/j.jeap.2016.06.002.

[18] S. Ebadi and M. Rahimi, "Mediating EFL learners' academic writing skills in online dynamic assessment using Google Docs," Comput. Assist. Lang. Learn., vol. 32, no. 5-6, pp. 527-555, Jul. 2019, doi: 10.1080/09588221.2018.1527362.

[19] D. Wu, W. Dang, D. He, and R. Bi, "Undergraduate information behaviors in thesis writing: A study using the Information Search Process model," J. Librariansh. Inf. Sci., vol. 49, no. 3, pp. 256-268, 2017, doi: $10.1177 / 0961000616654960$.

[20] A. I. Moreno and J. M. Swales, "Strengthening move analysis methodology towards bridging the function-form gap," English Specif. Purp., vol. 50, pp. 40-63, 2018, doi: 10.1016/j.esp.2017.11.006.

[21] M. Huerta et al., "Graduate students as academic writers: writing anxiety, self-efficacy and emotional intelligence," High. Educ. Res. Dev., pp. 1-14, 2016, doi: 10.1080/07294360.2016.1238881.

[22] A. D. Gedamu, "TEFL graduate supervisees' views of their supervisors' supervisory styles and satisfaction with thesis supervision," Iran. J. Lang. Teach. Res., vol. 6, no. 1, pp. 63-74, 2018.

[23] Y. Teklesellassie, "Views of summer TEFL postgraduate students and their supervisors on the practice of thesis supervision in the Ethiopian context," Pasaa, vol. 58, pp. 131-165, 2019.

[24] K. Filippou, J. Kallo, and M. Mikkilä-Erdmann, "Students' views on thesis supervision in international master's degree programmes in Finnish universities," Intercult. Educ., vol. 28, no. 3, pp. 334-352, 2017, doi: 10.1080/14675986.2017.1333713.

[25] Y. (Olivia) Zhang and K. Hyland, "Advice-giving, power and roles in theses supervisions," $J$. Pragmat., vol. 172, pp. 35-45, 2021, doi: 10.1016/j.pragma.2020.11.002.

[26] F. Strebel, S. Gürtler, B. Hulliger, and J. Lindeque, 
"Laissez-faire or guidance? Effective supervision of bachelor theses," Stud. High. Educ., vol. 46, no. 4, pp. 866-884, 2021, doi: 10.1080/03075079.2019.1659762.

[27] T. Karunaratne, "Blended supervision for thesis projects in higher education: A case study," Electron. J. e-Learning, vol. 16, no. 2, pp. 79-90, 2018.

[28] U. R. Averweg, "Enabling role of an intranet to augment e-coaching," Ind. Commer. Train., vol. 42, no. 1, pp. 47-52, 2010, doi: 10.1108/00197851011013715.

[29] T. H. Nasution, F. Pratama, K. Tanjung, I. Siregar, and A. Amalia, "Online thesis guidance management information system," J. Phys. Conf. Ser., vol. 978, no. 1, pp. 1-7, 2018, doi: 10.1088/1742-6596/978/1/012081.

[30] C. Casado-Lumbreras and R. Colomo-Palacios, "Online coaching in thesis supervision: A qualitative study," ACM Int. Conf. Proceeding Ser., pp. 489-495, 2014, doi: $10.1145 / 2669711.2669944$.

[31] U. Malaga-Toboła, I. Boulven, S. Kocira, A. Szparaga, and A. Henri, "The use of information sources and online databases for writing theses by students of selected studies," E3S Web Conf., vol. 132, pp. 3-8, 2019, doi: 10.1051/e3sconf/201913201017.

[32] B. Yazan, "Three Approaches to Case Study Methods in Education: Yin, Merriam, and Stake Three Approaches to Case Study Methods in Education: Yin , Merriam," Qual. Rep., vol. 20, no. 2, pp. 134-152, 2015, [Online]. Available: http://nsuworks.nova.edu/tqr/vol20/iss2/12.

[33] M. B. Miles, A. M. Huberman, and J. Saldana, Qualitative data analysis: A methods sourcebook. Thousand Oaks, California 91320: SAGE Publications, Inc., 2014.

[34] C. Barclay, C. Donalds, and K. M. Osei-Bryson, "Investigating critical success factors in online learning environments in higher education systems in the Caribbean," Inf. Technol. Dev., vol. 24, no. 3, pp. 582-611, 2018, doi: 10.1080/02681102.2018.1476831.

[35] N. Thongsri, L. Shen, and Y. Bao, "Investigating factors affecting learner's perception toward online learning: evidence from ClassStart application in Thailand," Behav. Inf. Technol., vol. 38, no. 12, pp. 1243-1258, 2019, doi: 10.1080/0144929X.2019.1581259.

[36] A. Bandura, "On the functional properties of perceived self-efficacy revisited," J. Manage., vol. 38, pp. 9-44, 2012. 